\title{
Glass-paper-laminates: examination of manufacturing methods, properties and discussion of potentials
}

\author{
Robert Götzinger $(\mathbb{D} \cdot$ Maximillian Hill $\cdot$ Samuel Schabel $(\mathbb{D} \cdot$ Jens Schneider $(\mathbb{C}$
}

Received: 8 September 2020/Accepted: 1 December 2020/Published online: 25 January 2021

(C) The Author(s) 2021

\begin{abstract}
This paper examines various ways of combining paper and glass as a laminate and the effects on transparency. Laminate in this context means a layer of paper sandwiched in between layers of glass held together with an adhesive. Different kinds of papers and adhesives were used to study the potentials of glass-paper-laminates as related to transparency and translucency. These laminates may find applications in building construction, safety glass, printed electronics and more. Utilizing a variety of adhesives and papers, qualitative evidence found that epoxy achieves the best with regards to transparency and adheres most effectively.
\end{abstract}

Keywords Glass · Paper - Lamination - Adhesive

\section{Introduction, motivation and research goals}

Due to sustainability goals it is important to increase the use of renewable resources. Developing

R. Götzinger $(\bowtie) \cdot$ M. Hill · S. Schabel

Institute of Paper Technology and Mechanical Process Engineering, Technische Universität Darmstadt, 64283 Darmstadt, Germany

e-mail: goetzinger@papier.tu-darmstadt.de

J. Schneider

Institute of Structural Mechanics and Design, Technische Universität Darmstadt, 64287 Darmstadt, Germany technologies and discovering new methods and materials that allow us to build with resources that are renewable and can be recycled will become a critical component for continued growth.

Paper is a desirable building material; it has a high stiffness to weight ratio and can be produced using a renewable resource, wood. That is why the project "BAMP! Building with Paper" has been running at the TU Darmstadt since 2017. Within the framework of this interdisciplinary project, the basics are created to make paper accessible as a construction material. The first case studies of the project, e.g. (Kanli et al. 2019), have already shown that paper has great potential to be established as a building material.

Glass is a naturally transparent material that has high stiffness and is wear-resistant, too. Glass is increasingly used in construction and architecture and is constantly being developed further for different applications (Schneider et al. 2016).

Even though paper is a material that will establish itself in the construction industry in the long run, basic research and standards are still needed to overcome its inherent weaknesses as moisture sensitivity and durable joining technologies. In an effort to create glass laminates that incorporate paper, the goal is to protect paper from, for example, moisture. On the other side, paper increases the number of applications and versatility of glass sheets ranging from shading applications, bird protection glass, and interior design. Function papers could also be considered such as 
printed electronics and sensors integrated into paper. Another motivation is to use the (resulting) material properties, of paper glass laminates to reveal the potential of these composites which could lead to completely new applications. It would also be conceivable to improve the recyclability of such laminates through appropriate functionalization of the paper in the composite.

The first aim of this paper is to find a suitable method to produce laminates made of glass and paper (Fig. 1). In a second step, the properties of various combinations of such laminates were to be investigated. Attention was given to transparency of the test specimens by relating its transparency to the papers Schopper-Riegler (SR) value. Further small demonstrations will then be used to show the characteristics of the laminates with varying paper quality to affect transparency and translucency. The findings will be used as an introduction to the topic of glass paper laminates in order to be able to go deeper into the subject.

\section{State of the art}

Paper and glass are very common and very widely used materials in a variety of industries. However, the lamination of glass to paper in the form of a sandwiched laminate, to create a glass-paper-laminate (GPL), is a relatively unexplored area. However, glass-paper-laminates with rice paper are used for interior design applications (Maxlen 2020). Understanding how paper affects transparency of GPLs is a logical starting point. The goal of this paper is to determine the effects of different adhesives and grades of paper on the transparency of that paper.

The basic idea of bonding paper with glass is not new. Laminating rice paper between two sheets of glass using Polyvinyl Butyral (PVB) or Ethylene

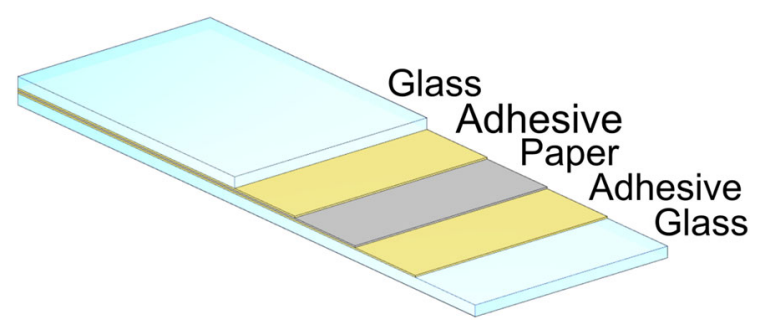

Fig. 1 Structure of glass- paper-laminates (GPLs)
Vinyl Acetate (EVA) is a common practice (Verrage Glass and Mirror Inc. 2015). Labels on bottles or jars are a good example of glass to paper bonding in everyday life. There is a large number of different adhesive systems for sticking labels onto glass. The difficulty of the present task results from the aim to produce a sandwich structure that is transparent, durable and load bearing. A major goal with respect to aesthetics is to create a GPL that does not contain any air inclusions (Wünsch 2017).

The paper Industry uses sodium silicate adhesives, or waterglas, as an adhesive for a variety of applications from paper tubes to more complex corrugated structures. Lübke et al. chose a comparable layout and combined glass with paper honeycomb panels using a sodium silicate as the adhesive (Lübke et al. 2018). Water glass and other dispersion adhesives are used, for example, in the production of paper cores (Herzau 2013). A widely used dispersion adhesive, polyvinyl acetate (PVAc), is used in the lamination of cardboard and corrugated board, the production of envelopes, corrugated board boxes, folding boxes, bags, sacks, sleeves, magazines and books (Brockmann et al. 2005). PVAc is also the basis of typical wood glues (Henkel 2017).

Such a wood glue (Henkel 2017) was also selected as the reference adhesive in the BAMP! project. This adhesive was selected due to its wide availability and quality. It can be applied in such a way that it either remains only on the surface or penetrates deeply into the paper structure. The adhesive boasts a good adhesive strength in dry as well as humid conditions.

PVB is a common polymer material used for glass laminates in fields such as construction and the automotive industry (Kuntsche et al. 2019). It is used as a lamination adhesive between float glass in order to improve safety and keeps its optical clarity. PVB can be purchased in either foil form or liquid form. Foils are most frequently used due to their ease of use. Foils are also superior as they can better guarantee an equal distribution of PVB across the desired surfaces (Zhang et al. 2015).

The combination of an epoxy resin with a hardener results in a thermoset irreversible compound that has good mechanical, chemical and thermal properties. Epoxy is used in a wide variety of industries including high tension electrical insulators, electronics including LED's, and adhesives (Wünsch 2017). Epoxy resin is subject of parallel research into paper as a lightweight 
construction material. These works build on that of Kröling (Kröling 2017).

\section{Experimental details}

The experiments conducted varied the type of paper used with respect to SR value, the type of adhesive use, and tested various types of lamination techniques ranging from hand assembled to industrial lamination presses.

\subsection{Glass}

The experiments used flat glass in three geometries, all rectangular prisms. The first were soda-lime-silica float glass plates, $10 \mathrm{~mm}$ nominal thickness with edge lengths of $95 \mathrm{~mm}$. Second, soda-lime glass microscope slides (Glaswarenfabrik Karl Hecht GmbH \& Co KG 2020) (76 mm by $26 \mathrm{~mm}$ by $1.2 \mathrm{~mm}$ ), were used due to their ease of availability, to create full laminates. Third, microscope slide covers $(24 \mathrm{~mm}$ by $32 \mathrm{~mm}$ by $0.13-0.17 \mathrm{~mm}$ ) were used in order to simulate thin glass laminates. Flatness was not measured.

\subsection{Adhesives}

A variety of bonding agents was tested. Adhesives tested include water, PVAc (Ponal Classic (Henkel 2017)), Sodium Silicate (waterglass, liquid) (Panreac 2011), Epoxy (Resin L-285, Hardener LH-287), PVB foil (Eastman 2015) and 10\% PVB in methanol liquid solution (made in the university lab). First, water was selected to determine if Van der Waals forces provided any useful mechanical adhesion. Standard tap water was used during tests. Second, PVAc was chosen as a recyclable and renewable adhesive option. Third, Sodium Silicate was selected as a binding agent due to its wide use in industry as an adhesive. Fourth, tests with PVB were carried out because it is the industry standard adhesive for glass lamination. For the purposes of this paper foil and liquid PVB were tested assuming that the liquid form could more easily be absorbed by the paper. Finally, Epoxy was tested because it cures as the result of a chemical reaction and not evaporation.

\subsection{Fibers and Papers}

Two strong indicators of paper transparency are the composition of the paper and the quality of the fibers used. Copy Paper contains mineral fillers. These cause the paper to become opaque. Unlike the fibers, mineral fillers do not become transparent when the paper is impregnated with another substance. In contrast, Transparent Paper has few minerals and the fibers can be highly beaten (Reinhold et al. 2015) to achieve the desired transparency. Accordingly, one standard Copy Paper and one standard transparent paper commonly found in stationery shops were included in the investigations. The two papers mentioned are in a similar grammage range (Copy Paper $80 \mathrm{~g} / \mathrm{m}^{2}$, Transparent Paper $90 \mathrm{~g} / \mathrm{m}^{2}$ ). Further data can be found in Table 3 in the result section. The values were measured according to the standards listed in Table 1 .

As mentioned before fibers in transparent paper can be highly beaten. Beating of the fibers influences the freeness, measured in Shopper-Riegler units (SR) (The freeness is a measure for the drainage behavior of a pulp). Another important factor is the fiber length (Reinhold et al. 2015). To exclude influences from industrial paper production, two types of laboratory isotropic handsheets were manufactured according to the DIN EN ISO 5269-2 standard. An eucalyptus pulp and two different degrees of beating were used in order to observe the effects of a low SR value and a high SR value on transparency. Initially, the pulp was defibered in a VOITH LR40 laboratory refiner and beaten to a freeness of $28 \mathrm{SR}$. For the second set of sheets the pulp was further beaten using a Valleybeater until it reached a freeness of $80 \mathrm{SR}$. The Valleybeater guarantees a slow, gentle beating. The pulp was further characterized with a fiber analyzer. The data can be taken from Table 2 .

A series of demonstration papers were created as well. These papers are not the primary focus of this paper, and were not tested, however represent an important milestone for the future of this technique. The three different demonstration papers were produced on an experimental sheet former described by Götzinger and Schabel in (Götzinger and Schabel 2019). All three were produced from Northern Bleached Softwood Kraft (NBSK) pulp with a freeness of approximately 26 SR. Refining was also carried out with the VOITH LR40 laboratory refiner. The first paper was produced purely from the pulp with 
Table 1 List of tests and their standards

\begin{tabular}{ll}
\hline Test & Standard \\
\hline $\begin{array}{l}\text { Pulps-determination of } \\
\text { drainability-Schopper-Riegler } \\
\text { method }\end{array}$ & DIN EN ISO 5267-1 \\
$\begin{array}{l}\text { Standard atmosphere for } \\
\text { conditioning and testing }\end{array}$ & DIN EN 20187 \\
Thickness & DIN EN ISO 534 \\
Ash content & ISO 2144, ISO 1762 or \\
& DIN 54370 \\
Transparency & DIN 53147 \\
Dispersion & DIN 54500 \\
Absorption & DIN 54500 \\
\hline
\end{tabular}

a $0.3 \%$ of fibers dyed with fluorescent dye used to evaluate the fiber orientation under UV light (see Fig. 5). The paper had a grammage of $60 \mathrm{~g} / \mathrm{m}^{2}$. The second paper contained $1 \%$ recycled carbon fibers and had a grammage of $30 \mathrm{~g} / \mathrm{m}^{2}$ (see Fig. 6 left). The third paper consists of three stripes. The left outer stripe is made of black colored fibers, the middle stripe of one part white and one-part blue fibers and the right outer stripe of white fibers (see Fig. 6 right). Each stripe had a target grammage of $50 \mathrm{~g} / \mathrm{m}^{2}$. The ability to produce paper with fiber direction control is a special feature of the experimental sheet former mentioned above. Papers with unidirectional fiber orientation have potential for providing as needed reinforcement dependent on project goals.

\subsection{Lamination}

Four various strategies were used to adhere the paper onto their glass substrates.

In the first test, the team tested samples at a variety of temperatures in order to determine the best temperature at which to cure specimen. Water, PVAc and Sodium Silicate were cured at $23{ }^{\circ} \mathrm{C}, 60^{\circ} \mathrm{C}$, $106{ }^{\circ} \mathrm{C}$ and $143{ }^{\circ} \mathrm{C}$. All specimen dried for a minimum of $24 \mathrm{~h}$. The specimen had no significant pressure applied to them however, a second float glass plate of similar size and shape was placed to the substrate on top of the lamination to prevented the paper from curling. A layer of silicon paper prevented sticking between the paper and the second float glass. Both the silicon paper and the second layer of glass were removed.

During the second strategy, a hydraulic press applied $9.8 \mathrm{MPa}$ of pressure for $5 \mathrm{~min}$ to a glasspaper-top glass sandwich comprised of the float glass substrate, the adhesive impregnated paper, a silicon sheet and a second float glass plate to ensure flatness. The specimen was removed from the press and then placed in an oven at $60{ }^{\circ} \mathrm{C}$ for $24 \mathrm{~h}$.

The third strategy was to use vacuum bags. The adhesive applied using this method was epoxy resin as epoxy activated by means of chemical reaction and does not require exposure to air. A vacuum bag of appropriate size contained a steel plate with a doublesided sticky tape to which the substrate was stuck. The epoxy was mixed and placed in a desiccator with vacuum attachments. The desiccator evacuation occurred 3 times for $5 \mathrm{~min}$ in order to remove bubbles. Paper segments cut to size got an epoxy coat on both sides before being positioned on the substrate. The structure then got a second glass segment placed on top and held in place using tape. Breather tissue strips were laid alongside each specimen so that the bag would not collapse and cut off the vacuum. A Leybold DIVAC 2.4L vacuum pump applied vacuum 3 times each for $5 \mathrm{~min}$, pressure was not measured. Following vacuum evacuation, the sample was placed in an oven at $60{ }^{\circ} \mathrm{C}$ to cure for $24 \mathrm{~h}$.

To counteract the problem of air bubbles in the paper during application with a brush the paper was first submerged in the resin and both were evacuated

Table 2 Comparison of the pulp properties of papers produced in the laboratory

\begin{tabular}{llllllll}
\hline $\begin{array}{l}\text { Sheet } \\
\text { name }\end{array}$ & Fiber type & $\begin{array}{l}\text { Freeness } \\
(\mathrm{SR})\end{array}$ & $\begin{array}{l}\text { Fiber length (length } \\
\text { weighted Lc(l)) }(\mathrm{mm})\end{array}$ & $\begin{array}{l}\text { Fiber width } \\
(\mu \mathrm{m})\end{array}$ & $\begin{array}{l}\text { Fiber curl } \\
(\%)\end{array}$ & $\begin{array}{l}\text { Fiber fibrillation } \\
(\%)\end{array}$ \\
\hline Euka 28 & Eucalyptus & 28 & 0.9 & 11.8 & 10.6 & 1.2 & Metso FS5 Fiber Analyzer \\
Euka 80 & Eucalyptus & 80 & 0.5 & 18.2 & 13.3 & 7.1 & Metso Fiberlab \\
\hline
\end{tabular}


together in the desiccator. Then the laminate was prepared as described above and the vacuum was applied for about $1 \mathrm{~h}$.

The fourth strategy incorporated the use of a lamination machine Lamipress Vario (Fotoverbundglas Marl GmbH 2020) and PVB. PVB is a resin adhesive and has a curing temperature higher than $100{ }^{\circ} \mathrm{C}$. The assembled specimen is placed between large silicon sheets creating an airtight seal and act as vacuum bags. Again, breather tissue was used from the vacuum attachment to the specimen location. This assembly was then placed in an airtight box. The Lamipress first evacuates all air from underneath the silicon cover to $-0.90 \mathrm{bar}$ for $20 \mathrm{~min}$ at $40{ }^{\circ} \mathrm{C}$. The temperature is increased to $150{ }^{\circ} \mathrm{C}$ and 1.0 bar of pressure is applied inside the box for $20 \mathrm{~min}$, vacuum holds at -0.50 bar. The Lamipress then equalizes the pressure in the vacuum region and the system cools to room temperature. When testing with foil PVB two configurations were tested. The first used one segment of PVB between the substrate and the bottom of the paper. The second used two segments on either side of the paper, between the glass (see Fig. 1). In the case of the samples with liquid PVB, the paper was impregnated with a brush, similar to the epoxy resin samples.

\section{Results and discussion}

\subsection{Paper properties}

As expected, transparency results (Table 3) show an increase in transparency with an increase in SR value. Euka 28 has an SR value of 28 is $16.09 \%$ less transparent than Euka 80 which has an SR value of 80 . The Vallybeater fibrillates the fibers of the pulp, during beating, allowing the fibers build in a way that is more space efficient. This is confirmed by a larger fiber width and a higher percentage of fibrillation with increased freeness, as shown in Table 2. Observing thickness measurements, it is evident that the higher SR paper has a thickness of $89.5 \mu \mathrm{m}$, which is $46.2 \mu \mathrm{m}$ thinner than the paper with a lower SR value, which has a thickness of $135.7 \mu \mathrm{m}$.

It should be noted that the Copy Paper has a significantly higher ash content at both $525^{\circ} \mathrm{C}$ and $900{ }^{\circ} \mathrm{C}$ then all other papers tested. Both the Transparent Paper as well as the Euka sheets have an ash content of less than $2.5 \%$. For the purpose of this analysis the Transparent Paper will be compared to the Euka 80 and Euka 28 laboratory sheets. The paper with the most transparency was the Transparent Paper with a value of $76.85 \%$. This is roughly twice that of
Table 3 Test results of various paper properties
$M$ mean, $S \mathrm{SD}$,

$V$ Coefficient of Variation

\begin{tabular}{|c|c|c|c|c|c|c|}
\hline Test & & Unit & Copy paper & Transparent paper & Euka 28 & Euka 80 \\
\hline \multirow[t]{3}{*}{ Transparency } & M & $\%$ & 15.15 & 76.85 & 21.56 & 37.65 \\
\hline & $\mathrm{S}$ & $\%$ & 0.51 & 0.95 & 0.63 & 0.47 \\
\hline & $\mathrm{V}$ & $\%$ & 3.39 & 1.24 & 2.90 & 1.24 \\
\hline \multirow[t]{3}{*}{ Thickness } & M & $\mu \mathrm{m}$ & 104.7 & 75.35 & 135.7 & 89.5 \\
\hline & $\mathrm{S}$ & $\mu \mathrm{m}$ & 1.56 & 1.53 & 6.23 & 2.14 \\
\hline & $\mathrm{V}$ & $\%$ & 1.49 & 2.03 & 4.59 & 2.39 \\
\hline \multirow[t]{3}{*}{ Ash Content $525^{\circ} \mathrm{C}$} & M & $\%$ & 22.84 & 2.40 & 0.49 & 0.62 \\
\hline & $\mathrm{S}$ & $\%$ & 0.68 & 0.05 & 0.06 & - \\
\hline & $\mathrm{V}$ & $\%$ & 2.97 & 2.07 & 11.54 & - \\
\hline \multirow[t]{3}{*}{ Ash Content $900^{\circ} \mathrm{C}$} & M & $\%$ & 14.28 & 2.34 & 0.36 & 0.5 \\
\hline & $\mathrm{S}$ & $\%$ & 0.30 & 0.04 & 0.06 & - \\
\hline & $\mathrm{V}$ & $\%$ & 2.13 & 1.81 & 17.93 & - \\
\hline \multirow[t]{3}{*}{ Light Scattering } & M & $\mathrm{m}^{2} / \mathrm{kg}$ & 60.69 & 3.11 & 41.65 & 19.05 \\
\hline & $\mathrm{S}$ & $\mathrm{m}^{2} / \mathrm{kg}$ & 1.58 & 0.19 & 1.47 & 0.44 \\
\hline & $\mathrm{V}$ & $\%$ & 2.61 & 6.27 & 3.54 & 2.29 \\
\hline \multirow[t]{3}{*}{ Absorption } & M & $\mathrm{m}^{2} / \mathrm{kg}$ & 0.71 & 0.15 & 0.24 & 0.49 \\
\hline & $\mathrm{S}$ & $\mathrm{m}^{2} / \mathrm{kg}$ & 0.04 & 0.01 & 0.01 & 0.01 \\
\hline & $\mathrm{V}$ & $\%$ & 6.13 & 6.05 & 3.09 & 1.51 \\
\hline
\end{tabular}


Table 4 Graphical representation of data in Table 3

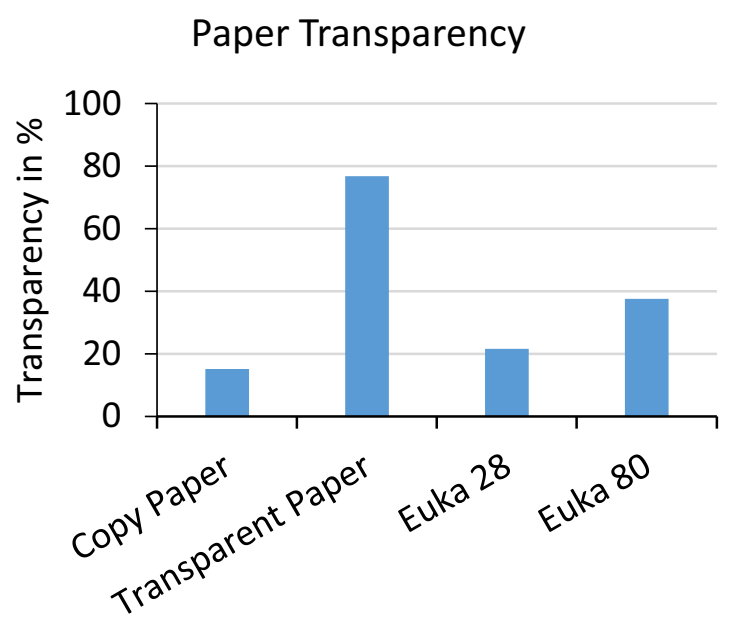

Paper Ash content $525^{\circ} \mathrm{C}$

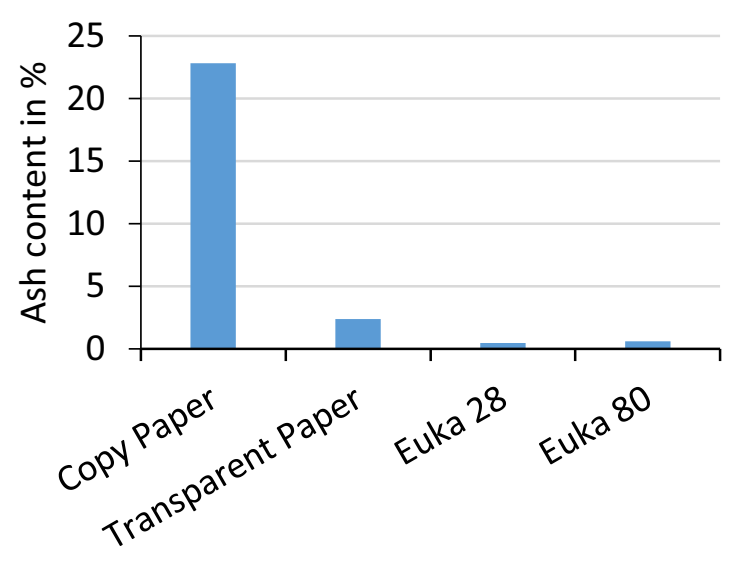

the Euka 28 at $37.65 \%$ and three times that of Euka 80 at $21.56 \%$. Table 4 shows that there is an inverse relationship between transparency and paper thickness. Thinner papers have higher transparency. The transparency of the Transparent Paper is highest and is also the thinnest of the papers measuring $75.35 \mu \mathrm{m}$. In comparison the Euka 80 measures $135.7 \mu \mathrm{m}$ and the Euka $2889.5 \mu \mathrm{m}$.

\subsection{Laminates}

All results and conclusions pertaining to the laminates are qualitative and based on observations since a

\section{Paper thickness}

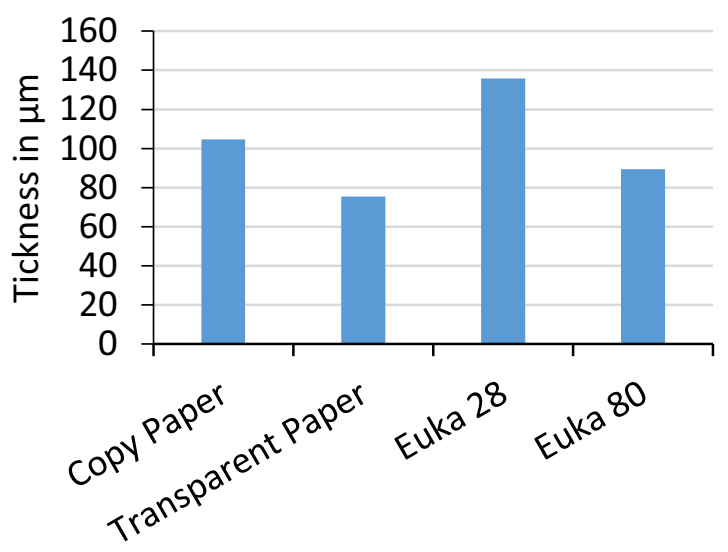

Paper transparency over thickness

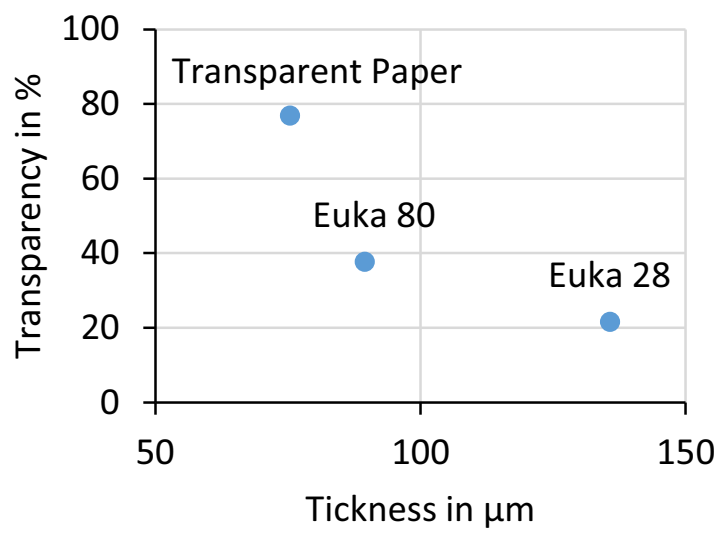

detailed mechanical and ageing investigation of the laminates could not take place yet.

The use of water was the least effective of all the laminates as the water fully evaporated and all bonds were easily broken at any temperature.

During the adhesion of waterglass and polyvynalacetate problems arose during the drying process. With both pieces of glass covering the paper it was very difficult for the water to escape creating a very significant time dependency. The inconsistent drying also introduced visible stress patterns in the paper. Qualitative results show that $60{ }^{\circ} \mathrm{C}$ provided best results. Lower temperatures took excessively long to 
cure (more than one week). Using the hydraulic press did not appreciably reduce the number and size of bubbles between the substrate and paper. Nor did it appreciably increase adhesion. The use of the press led to the disassociation of the paper in most of the tests. Higher temperatures led to discoloration of PVAc and Sodium Silicate. Water-based solutions were therefore not considered further.

The use of PVB in liquid solution and Epoxy adhesive has been shown to be most effective. The PVB foil does not penetrate the paper sufficiently by melting. It is not possible to work with only one layer of lamination, but both sides of the paper must be covered with foil to provide sufficient adhesion to the two glass surfaces. Epoxy and liquid PVB showed the best results regarding minimizing the occurence of air bubbles because they are able to penetrate into the small pores of the paper. Air bubbles affect the optical quality and the structure of the laminates.
The Lamipress process consistently produced the best results regarding cleanliness, homogeneity of the samples and low air bubble formation in the samples.

Figure 2 shows a comparison of laminates with Copy Paper and various adhesives. It becomes clear that the transparency is significantly influenced by the adhesive. The use of epoxy resin makes the copy paper much more transparent than would be expected from the measured values for transparency on the paper. Even with liquid PVB a slight transparency can be seen. The increased transparency can be explained by the good penetration of the liquid adhesives into the paper compared to the poor penetration when using PVB foil.

As is to be expected, the transparency of the finished laminates is highest with transparent paper (Fig. 3). Here, both the liquid adhesives and the adhesive foil show high transparency. The picture is clearest with epoxy resin.
Fig. 2 Laminates with Copy Paper. Left: Epoxy. Middle: Two layers PVB foil. Right: Liquid PVB. Glass thickness $2 \cdot 1.2 \mathrm{~mm}$
Fig. 3 Laminates with Transparent Paper. Left: Epoxy. Middle: Two layers PVB foil. Right: Liquid PVB. Glass thickness $2 \cdot 1.2 \mathrm{~mm}$ rem ipsum dolor sit amet, consetetur sadipscing elitr, sed diam nonum ,ore et dolore magna aliquyam erat. sed diam voluptua. At vero eos et

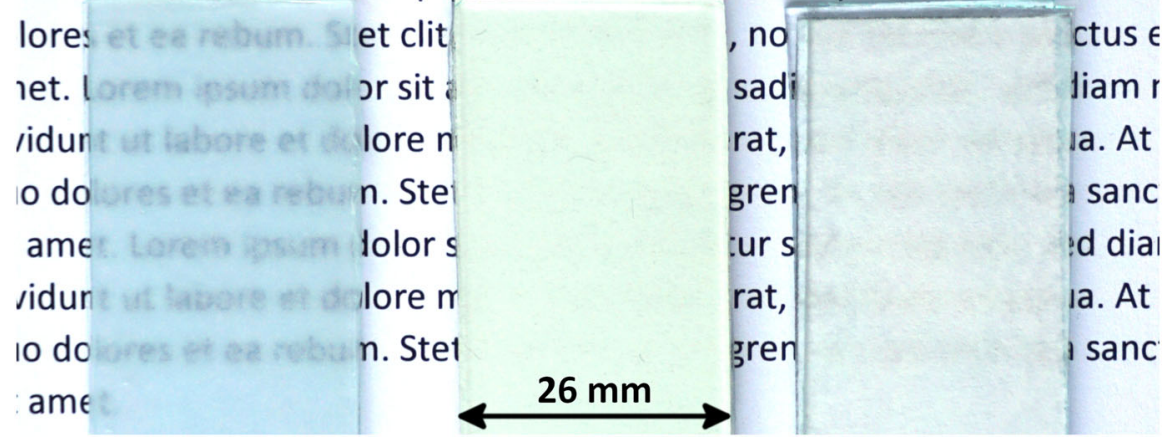

$\mathrm{m}$ ipsum dolor sit amet, consetetur sadipscing elitr, sed diam nonu re et dolore magna aliquyam erat, sed diam voluptua. At vero eos 1 res et ea rebum. Stet clit i kasd gubergren, no sea takimata sanctus t. Lorem ipsum dolor sit i met, consetetur sadipscing elitr, sed dian unt ut labore et dolore niagna aliquyam erat, sed diam voluptua. f dolores et ea rebumı. Ste clita kasd gubergren, no sea takimata saı net Lorem ipsum dolor sit amet, consetetur sa dipscing elitr, so $\mathbf{d} \mathbf{d}$ lunt ut labore et dolore niagna aliquyam erat, sed diam voluptua. f dolores et ea rebum. Ste clita kasd gubergren, no sea takimata sar net. $26 \mathrm{~mm}$ 
The same observations as described above can be made on the laboratory papers Euka 28. Surprisingly, in Fig. 4 the laminate with the paper Euka 80 has a poorer transparency than the one with Euka 28. Whether the lamination process produces different properties than those obtained from the paper measurements needs further investigation.

First qualitative light transmission measurements confirm the results described here by purely visual observations. In order to create reliable data and exclude boundary effects, further samples with larger dimensions have to be produced.

For all observations a correlation with the thickness of the laminates must be considered and quantified in further experiments.

Figure 5 shows a laminate with highly oriented paper into which tracer fibers have been incorporated. At the top of the picture a good transparency towards a text can be seen. Compared to a black background, no fibers and colors are visible (middle), but when UVlight is switched on (bottom), the colored fibers are clearly visible. These fibers are an example of arbitrary functionalization which can be inserted into the middle layer of such a glass-paper laminate.

Figure 6 shows on the left side the result with carbon fiber paper. Despite the black carbon fibers, a good transparency is retained. The fibers are only slightly visible. If necessary, the proportion of carbon fibers can be increased further without being visually disturbing. In the multicolored paper shown to the right, wire marks from the paper are visible in the black strip (The black strip appears dark blue in the image). They cause air bubbles to form which then disturb the visual impression. In order to obtain a clear picture, it is necessary to optimize the process. Nevertheless, it can be successfully demonstrated here which possibilities exist for using the paper from the newly developed sheet former.

\section{Summary and outlook}

Different kinds of papers and adhesives were used to study the potentials of glass-paper-laminates as related to transparency and translucency. The adhesives used included Polyvinyl acetat (PVAc), Sodium Silicate, Epoxy and Polyvinyl Butyral (PVB). It turned out that the use of PVB and Epoxy adhesives activated by thermoplastic or chemical reactions are most effective.

As described in the state of the art, PVB is usually used as a foil. However, the results show that the use of

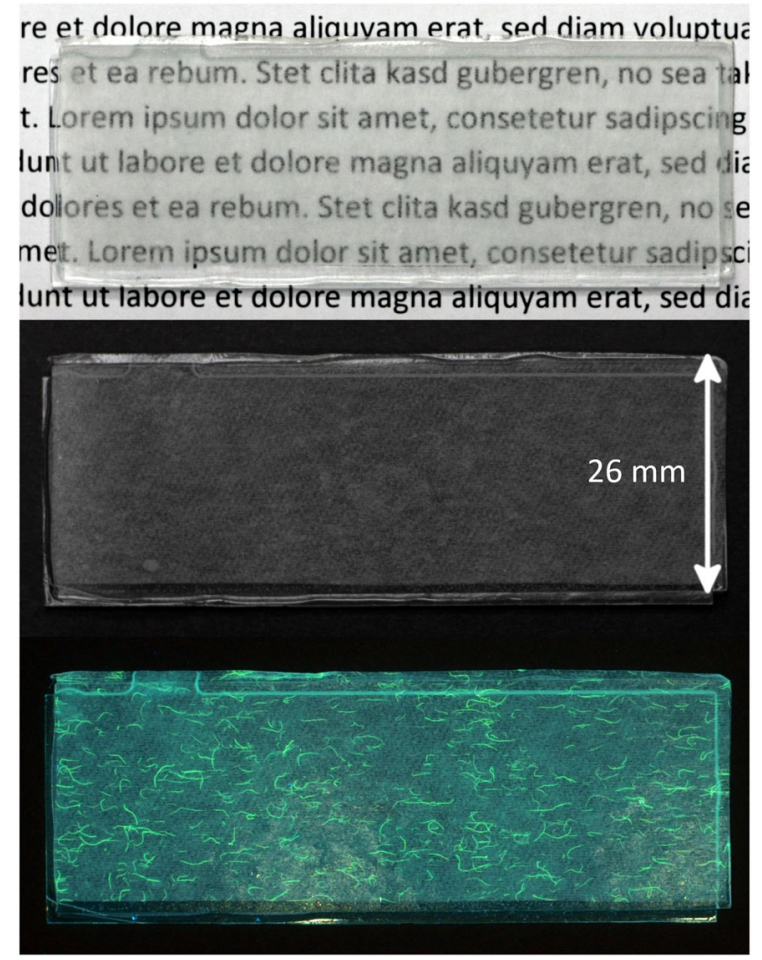

Fig. 5 Laminate with oriented paper, tracer fibers and Epoxy. Glass thickness $2 \cdot 1.2 \mathrm{~mm}$. Bottom picture taken under UV-light
Fig. 4 Laminates with eucalyptus handsheets. Left: Euka 80 Epoxy. MiddleLeft: Euka 28 Epoxy. Middle-Right: Euka 28 Two layers PVB foil. Right: Euka 28 Liquid PVB. Glass thickness $2 \cdot 1.2 \mathrm{~mm}$ rem ipsum dolor sit amet, consetetur sadipscing elitr, sed diam nonumy eirmod tempor in bore et dolore magna aliquyam erat, sed diam voluptua. At vero eos et accusam et justo dı olores et clita kasd gubergren, no ctus dol met. L or sit amet, consetetursad Ividun thase ex magna aliquyam erat, uo do $r$. Stest clita kasd gubergren t ame dolor sit amet, consetetur s ıvidun alo colore magna aliquyam erat, uo do m. Stet clita kasd gubergren t ame $26 \mathrm{~mm}$ $\begin{array}{ll}\text { ctus } & \text { dol } \\ \text { diam } & \text { ter } \\ \text { Ia. At } & \text { san } \\ \text { I san } & \text { sum } \\ \text { d dic } & \text { d t } \\ \text { la. At } & \text { san } \\ \text { san } & \text { sum }\end{array}$ 
re et dolore magna aliquyam erat, sed diam voluptua. At res et ea rebum. Stet clita kasd gubergren, no sea dime t. Lprem ipsum dolor sit amet, consetetur sadipsci $g$ elit। un. ut labore et dolore magna aliquyam $\mathbf{2 6} \mathbf{~ m m}$ iò $\mathrm{m} \mathrm{v}$ dolores et ea rebum. Stet clita kasd gubergren, no ea ta ne. Lorem ipsum dolor sit amet, consetetur sadif ing $\epsilon$ unt ut labore et dolore magna aliquyam erat, sed diam $v$

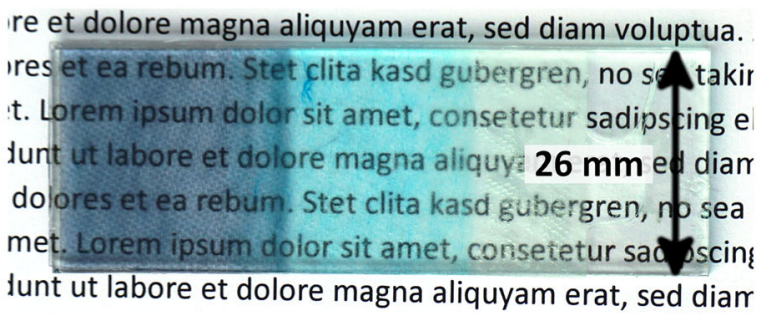

Fig. 6 Left: Laminate with carbon fiber paper and Epoxy. Right: Laminate with three-colored paper and Epoxy. Glass thickness $2 \cdot 1.2 \mathrm{~mm}$

foil between glass and paper does not lead to sufficient penetration of the paper and thus to poor adhesion. Therefore, the use of PVB in liquid form is recommended. In one of the next steps it will be tested whether the paper itself can first be pre-impregnated with liquid PVB, dried and later melted to take over the function of the foil. Compared to conventional processes, this could also have the advantage of saving PVB material.

It could be shown that the properties transparency and translucency can be influenced by the right choice of paper and adhesive in GPLs. This could be used to control the incidence of light in architectural applications or even in greenhouses. The incidence of light can be specifically controlled by clever combination and shifting of laminates with different transparency and translucency properties as shown on the right in Fig. 6.

Glass protects the layers of paper inside a GPL from external influences. The same applies of course to everything that is applied to the paper before lamination. The technique for printing on paper is very mature and offers a large number of possibilities. Besides printing for purely aesthetic purposes, functional prints such as printed electronics are also conceivable. It may be possible to integrate paperbased sensors in the glass. All this requires further investigation.

Furthermore, in next steps it must be checked whether the fibers are capable of bridging cracks in glass. This could be applied in laminated safety glass. Great potential could be found here in blends of synthetic fibers, such as carbon fibers, and paper fibers (Fig. 6 left). An exact consideration of the mechanical and fracture mechanical properties will be necessary for this.

A first idea why laminates of glass and paper could have advantages was to improve the recyclability of laminated glass. Therefore, further research is needed to find a way to separate the laminates again. For the solution approach, potential can be seen in the functionalization of the paper fibers.

Acknowledgements The authors of this paper would like to acknowledge Marcel Hörbert (ISMD) for his help with the Lamipress. We would also like to thank Nicole Panzer (PMV), Andreas Striegel (PMV), Michael Drass (ISMD) and Matthias Seel (MPA-IfW) for helping conduct experiments and run tests.

Funding Open Access funding enabled and organized by Projekt DEAL.

Availability of data and material Data available at PMV, TU Darmstadt.

\section{Compliance with ethical standards}

Conflicts of interest On behalf of all authors, the corresponding author states that there is no conflict of interest.

Open Access This article is licensed under a Creative Commons Attribution 4.0 International License, which permits use, sharing, adaptation, distribution and reproduction in any medium or format, as long as you give appropriate credit to the original author(s) and the source, provide a link to the Creative Commons licence, and indicate if changes were made. The images or other third party material in this article are included in the article's Creative Commons licence, unless indicated otherwise in a credit line to the material. If material is not included in the article's Creative Commons licence and your intended use is not permitted by statutory regulation or exceeds the permitted use, you will need to obtain permission directly from the copyright holder. To view a copy of this licence, visit http://creativecommons.org/licenses/by/4.0/.

\section{References}

Brockmann, W., Geiß, P. L., Klingen, J., \& Schröder, B.: Anwendungen der Klebtechnik. In: Klebtechnik: Klebstoffe, Anwendungen und Verfahren. Wiley-VCH, Weinheim (2005) 
Eastman.: Product Technical Data: Saflex R-Polyvinyl Butyral Inerlayer (2015)

Fotoverbundglas Marl GmbH.: Datenblatt: LAMIPRESS ${ }^{\circledR}$ VARIO (2020)

Glaswarenfabrik Karl Hecht GmbH \& Co KG.: ObjektträgerChemische und physikalische Eigenschaften (2020)

Götzinger, R., Schabel, S.: Production and Evaluation of Paper with High Fiber Orientation for Paper-Based Construction Materials. Paper presented at the PaperCon 2019 Conference, Indianapolis (2019)

Henkel.: Datenblatt: Ponal Classic. In: Henkel AG \& Co. KGaA (2017)

Herzau, E.: Herstellung von Rundgefäßen und gewickelten Hülsen. In: Blechschmidt, J. (ed.) Papierverarbeitungstechnik, pp. 481-495. Carl Hanser Verlag GmbH \& Co. KG, München (2013)

Kanli, E., Bach, R., Götzinger, R., Kiziltoprak, N., Knaack, U., Schabel, S., Schneider, J.: Case study: development and evaluation methods for bio-based construction realized with paper-based building materials. In: ICBBM 2019 Proceedings of the 3rd International Conference on BioBased Building Materials. 75016 Paris, France: RILEM Publications S.a.r.1, pp. 682-689 (2019)

Kröling, H.: Paper as Reinforcement in Paper-Epoxy Composits and All-Cellulose Composites. (Dr.-Ing Dissertation). TU Darmstadt, Darmstadt (2017)

Kuntsche, J., Schuster, M., Schneider, J.: Engineering design of laminated safety glass considering the shear coupling: a review. Glass Structures \& Engineering 4(2), 209-228 (2019)
Lübke, J., Wettlaufer, M., Kiziltoprak, N., Drass, M., Schneider, J., Knaack, U.: Honeycomb-Paperboard Glass Composite Beams. ce/papers 2(5-6), 57-69 (2018)

Maxlen.: Wallpaper, Parchment and Rice paper (2020). http:// www.maxlen.co.uk/Wallpaper\%20and\%20Parchment\% 20glass.htm

Panreac.: Sicherheitsdatenblatt: 1714 Natriumsilicat *Neutrallösung (2011)

Reinhold, T., Bartsch, J., Geiger, G.A.: Papier ABC. Verband Deutscher Papierfabriken, Bonn (2015)

Schneider, J., Wörner, J.-D., Schneider, F., Schula, S., Kuntsche, J.: Werkstoff Glas. In: Schneider, J., Kuntsche, J., Schula, S., Schneider, F., Wörner, J.-D. (eds.) Glasbau: Grundlagen, Berechnung, Konstruktion, pp. 1-25. Springer, Berlin (2016)

Verrage Glass and Mirror Inc.: Laminated glass (2015). http:// www.verrage.com/laminatedglass.html

Wünsch, J.: Transparente Epoxidharzklebstoffe für Glas-Metall-Verbindungen. (Dr.-Ing. Dissertation). Technische Universität Dresden, Dissertation (2017). https://nbnresolving.org/urn:nbn:de:bsz:14-qucosa-234030

Zhang, X., Hao, H., Shi, Y., Cui, J.: The mechanical properties of Polyvinyl Butyral (PVB) at high strain rates. Constr. Build. Mater. 93, 404-415 (2015). https://doi.org/10.1016/ j.conbuildmat.2015.04.057

Publisher's Note Springer Nature remains neutral with regard to jurisdictional claims in published maps and institutional affiliations. 